\title{
Design Interface - The Nexus of Engineering and Product Support
}

\author{
Patrick M. Dallosta, CPL, Defense Acquisition University \\ Thomas A. Simcik, CPL, CPIM, United States Navy
}

Key Words: design interface, design, reliability, availability, maintainability, suitability, supportability, trade studies

\section{SUMMARY \& CONCLUSIONS}

The paper defines the Design Interface process by which system design characteristics of Reliability and Maintainability are analyzed and trade studies conducted to influence the design to meet operational and sustainment requirements. Given that the total cost of Reliability may account for as much as $60 \%$ of a system's life Cycle Cost [1], emphasis on reducing the impact of Reliability related cost drivers during the early phases of product development is an imperative for the Program Management, Systems Engineering and Product Support communities.

\section{INTRODUCTION}

\subsection{Design Interface Parameters}

Design Interface is the relationship of the system design characteristics of Reliability and Maintainability to Operational Effectiveness and Suitability.

Operational effectiveness is the overall degree of mission accomplishment of a system when used by representative personnel in the environment planned or expected for operational employment of the system considering organization, doctrine, survivability, tactics, vulnerability, and threat.

Operational Suitability is the degree to which a system can be satisfactorily placed in field use, with consideration given to reliability, availability, compatibility, transportability, interoperability, wartime usage rates, maintainability, safety, human factors, manpower supportability, logistics supportability, documentation, training requirements, and natural environmental effects and impacts.

The paper addresses design interface as a critical part of the complex systems engineering activities integral to product development. As such, Design Interface is a primary driver of Supportability Analysis trade studies that are conducted to ensure supportability is included as a system performance requirement and that the system is concurrently designed, developed and acquired with the optimal product support infrastructure and resources. The system's Supportability requirements are identified and developed through the application of the Design Interface processes.

\subsection{Design - Supportability Relationships}

As defined in the Naval Air Systems Command's Standard Work Package (SWP) 6711-001C, Design Interface
Process [2], Design Interface is a complex process integral to both Systems Engineering and Product Support activities during the Product Development phase.

Design Interface processes identify and develop both system performance and Supportability requirements by addressing the following three relationships that are directly linked to how a system is designed for Supportability to determine the degree to which:

- Components or sub-systems within the system are designed and interfaced to achieve the best mix and/or what design trade-off are available among the support elements themselves, to include maintenance, supply support, facilities, and transportation.

- The overall supportability design of the system interfaces with other systems and services external to the system itself, to include interoperability, standardization, and commonality.

- Supportability design parameters address operational effectiveness and suitability requirements, to include reliability, maintainability, availability, interoperability, human systems integration, environmental impact and asset visibility.

These three relationships impact how the support system design achieves readiness, ownership cost and logistics footprint objectives. DI develops and conducts the primary integration functions to ensure a smooth, seamless system design process.

\subsection{Supportability Analysis Life Cycle Framework}

Figure 1, Supportability Analysis Life Cycle Framework, illustrates the Supportability Analysis activities and their relationships, and serves as the framework for the conduct of Design Interface and other Supportability Analysis activities. The Framework is described in terms of three distinct, yet integrated processes as described in the following paragraphs.

\subsubsection{Design for Support}

Design Interface activities are principally conducted within the first process, "Design for Support. Design Interface decisions made "up front" during the early phases have a profound effect on life cycle cost As discussed in the CAIG Report, design decisions made by Milestone B establish a "cost commitment" of approximately 70 percent of a system's LCC, while actual "cost expended" values are still a small percentage of total expenditures. "Design for Support" 


\section{DESIGN FOR SUPPORT DESIGN THE SUPPORT SUPPORT THE DESIGN}

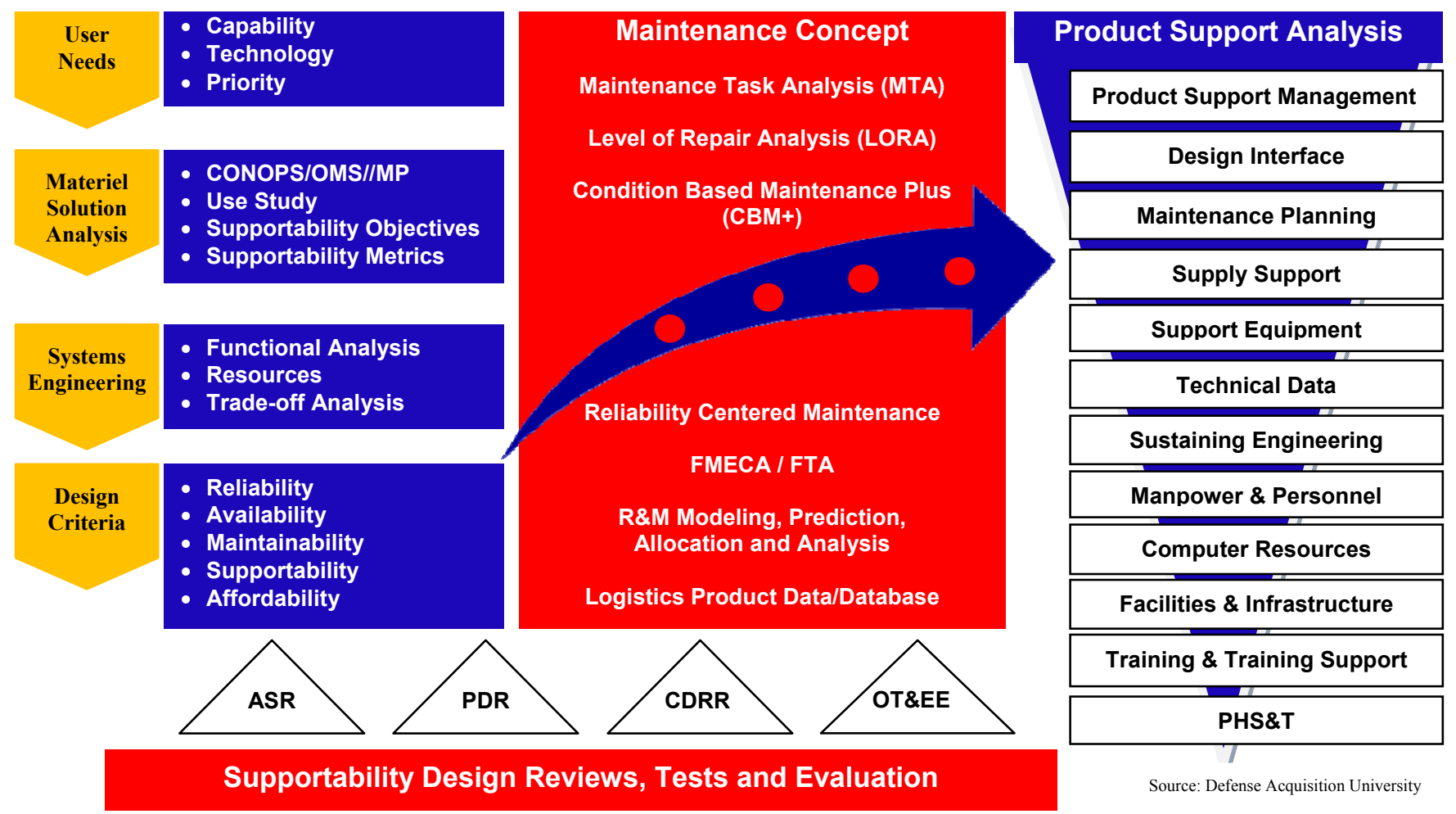

Figure 1 - Supportability Analysis Life Cycle Framework

During this phase, supportability objectives, their associated metrics, and the initial trade studies are conducted within the Systems Engineering/Life Cycle Logistics process and result in the preferred system design and sustainment architectures with specific design criteria.

Key to these activities is the development of the maintenance concept, which specifies the levels of maintenance and their capabilities and assigns the preventive and corrective tasks to be accomplished at each level. The maintenance concept provides the construct by which systems engineering/life cycle logistics tasks are conducted. The tasks include Reliability and Maintainability (R\&M) Modeling, Prediction, Allocation and Analysis; Failure Mode, Effects and Criticality (FMECA); Fault Tree Analysis (FTA); Condition-Based Maintenance Plus ( $\mathrm{CBM}+)$, and Reliability Centered Maintenance (RCM). The output of these tasks is the assessment of the impact of the system's R\&M design characteristics on performance and sustainment. Improvements in RAM are achieved by the elimination of single points of failure, improved mean time be-tween failure (MTBF) through the use of redundancy, and the reduction of mean time to repair (MTTR), through the implementation of accessibility, modularity and testability concepts. Overall reductions in maintenance are also achieved by $\mathrm{CBM}+$ and RCM programs that focus on conducting maintenance based on the evidence of need rather than defined schedules.
From both a cost and logistics perspective, the level of repair analysis (LORA) is the most important business decision made in the program office. The LORA uses the detailed maintenance information provided by the maintenance task analysis (MTA), as well as operational factors and economic criteria to allocate the repair/disposal actions throughout the levels of maintenance, and to provide an LCC estimate for use in decision making. The LORA provides the information needed to finalize the maintenance concept as well as initiate maintenance planning activities.

\subsubsection{Design the Support}

The second process, "Design the Support" is based on the output of the design for support process as described previously-i.e., the spares, common, peculiar, and unique tools and discrete and automatic test equipment, facilities, and maintenance training that must be specified and procured.

For example, Support Equipment Recommendation Data (SERD) is generated as part of the Product Support Analysis (PSA) process to specify measurement requirements and determine if existing equipment can be used or whether new equipment must be designed and procured. A properly tailored Product Support Package, based on the technical requirements of the system, will yield the most affordable and operationally ready capability. 


\subsubsection{Support the Design}

The third process, "Support the Design" is implemented through the resources of the Integrated Product Support (IPS) Package as illustrated and as discussed in Appendix A of the DoD Product Support Manager (PSM) Guidebook [3] and is the ultimate outcome of the supportability analysis process. As shown in Figure 1, the 12 IPS elements are defined as a result of a robust Product Support Analysis and provide the assets required for effective sustainment of the system.

\section{DESIGN CONSIDERATIONS}

\subsection{Availability}

Availability is the measure of the degree to which an item is in an operable state and ready-for-use at the start of a mission or operation [4].

From a Design Interface perspective, Inherent Availability $\left(\mathrm{A}_{\mathrm{I}}\right)$ addresses the ability of a design to be restored to operating status as solely as a function of the design characteristics of Reliability and Maintainability. Inherent Availability reflects the system's reliability in terms of Mean Time Between Failure, and the system's Maintainability in terms of Mean Corrective Maintenance Time (Mct), which reflects the system's design for accessibility, modularity and testability in an ideal support environment by excluding preventive or scheduled maintenance actions, logistics delay time and administrative delay time. $A_{I}$ is expressed as:

$$
\mathrm{A}_{\mathrm{I}}=\mathrm{MTBF} /(\mathrm{MTBF}+\underline{\mathrm{Mct}})
$$

Operational Availability $\left(\mathrm{A}_{\mathrm{O}}\right)$ builds on this model and includes the effect of preventive and corrective maintenance, as well as logistics and administrative delay times. $A_{O}$ is expressed as:

$$
\mathrm{A}_{\mathrm{O}}=\mathrm{MTBM} /(\mathrm{MTBM}+\mathrm{MDT})
$$

Where MTBM is the Mean Time Between Maintenance (including preventive and corrective) and MDT is the Mean Maintenance Down Time.

As such Operational Availability models the impact of the Product Support system on Availability, and thereby serves as a forcing function to optimize sustainment.

\subsection{Reliability}

Reliability is the probability that an item will perform its intended function for a specified interval under stated conditions [5]. Reliability is a prime driver of support resources. Products with high reliability are usually cost effective. The design of a product could be made that reduces and compensates for the implication of a low reliability so when a failure occurs, it is easy to locate the failure and easy to perform corrective actions. To maintain availability, it is to some extent possible to compensate low reliability with increased maintainability and supportability.

\subsection{Maintainability}

Maintainability is the relative ease and economy of time and resources with which an item can be retained in, or restored to, a specified condition when maintenance is performed by personnel having specified skill levels, using prescribed procedures and resources, at each prescribed level of maintenance and repair [6]. Maintainability as a design activity implements the three capabilities of accessibility, modularity and testability to minimize downtime.

\subsection{Testability}

Testability [7] addresses the extent to which a system or unit supports fault detection and fault isolation in a confident, timely and cost-effective manner. The incorporation of adequate testability, including built-in test (BIT), requires early end systematic management attention to testability requirements, design and measurement.

\subsection{Diagnostics and Prognostics}

Condition Based Maintenance Plus $(\mathrm{CBM}+)$ [8] is a comprehensive strategy involving the "application and integration of appropriate processes, technologies, and knowledge based capabilities to improve the reliability and maintenance effectiveness of DoD systems and components. $\mathrm{CBM}+$ focuses on the performance of maintenance based on the evidence of need and implements technology to identify predictive or 'pro-active' maintenance requirements to prolong system life and decrease maintenance costs.

\subsection{Standardization}

Standardization is coordination of resources through the establishment of common or compatible technical procedures and criteria, and common, compatible or interchangeable supplies, components, weapons or equipment [9]. Standardization reduces cost when an existing part or system provides a capability, thereby negating the need for development. The use of standardized Support Equipment (SE) decreases logistics resource requirements.

\subsection{Interoperability/Interchangeability}

Modular Open Systems Architecture (MOSA) requirements provide the ability of equipment at several levels of indenture to be interchangeable (useable) between systems, and is a design requirement that must be established prior to the start of any design activity.

\subsection{Environmental Considerations}

Environmental considerations include man-machine interfaces by both personnel and systems with natural and artificial environments, as well as requirements for environmental controls. These considerations may directly impact design requirements and design practices, operational concepts, doctrine, the support environment and Environmental, Safety and Occupational Health (ESOH) asset requirements.

\subsection{Human Factors/Ergonomics}

Human Systems Integration (HSI) is conducted to optimize total system performance and minimize life-cycle 
costs. HSI domains include manpower, personnel, training, human factors engineering, environment, safety, occupational health, survivability, and habitability considerations that must be addressed to design systems and incorporate technologies that:

- Require minimal manpower

- Provide effective training

- Can be operated and maintained by users

- Are suitable (habitable and safe with minimal environmental and occupational health hazards)

- Are survivable (for both the crew and the equipment)

\subsection{Obsolescence}

Parts management is a design strategy that seeks to reduce the number of unique or specialized parts used in a system (or across systems) to reduce the logistic footprint and lower total Life Cycle Costs. In addition, it also will enhance the reliability of the system and mitigate parts obsolescence because of Diminishing Manufacturing Sources and Material Shortages.

Parts management is an important design consideration and should be used whenever parts are not defined based on open systems design interfaces. The parts management strategy should cover the entire life cycle of a system and be based on the fundamental systems engineering processes, and documented in a Parts Management Strategy. The parts management strategy should also be evaluated at Technical Reviews, in particular, the Preliminary Design Review and Critical Design Review.

\subsection{Supportability}

Supportability is the degree to which system design characteristics and planned logistics resources meet operational and sustainment requirements. Supportability Analysis is a process used to determine an item/system's support needs and preferred support methods. The Supportability Analysis processes uses the reliability and maintainability, operational requirements, existing support systems and integrated product support objectives as inputs and it outputs an integrated life cycle product support infrastructure for the system.

Supportability analysis is conducted to ensure supportability is included as a system performance requirement and that the system is concurrently designed, developed and acquired with the optimal support system and infrastructure in order to:

- Reduce the demand for logistics

- Provide any required logistics efficiently and effectively

\subsection{Software}

The complexity of software in modern systems may equal or exceed that of hardware. From a Design Interface perspective, there is little, if any difference in the application of analyses such as Reliability Modeling and Prediction, Failure Mode Effects and Criticality Analysis and Fault Tree Analysis. The total system failure rate is now equal to the sum of the hardware and software failure rates.

\subsection{Cost Effectiveness/Affordability}

DoD policy has been recently updated to include the specification of "Should Cost" and "Will Cost" Affordability targets [10] within the Affordability construct of the "Better Buy Power" Memorandum [11]. This effort works to take advantage of both process efficiencies as well as best practices to reduce both acquisition and sustainment costs.

\section{DESIGN INTERFACE PROGRAM ACTIVITIES}

The following Program activities are typical of the approach conducted to achieve Design Interface objective of influencing the design to achieve both performance, i.e., Reliability \& Maintainability as well as Supportability, i.e., Product Support resources.

\subsection{Analysis of Alternatives (AoA)}

As discussed in the Defense Acquisition Guidebook (DAG) [12], the Analysis of Alternatives (AoA) is an important element of the defense acquisition process. An (AoA) is an analytical comparison of the operational effectiveness, suitability, and life-cycle cost, of alternatives that satisfy established capability needs.

Initially, after the Materiel Development Decision (MDD), the (AoA) is initiated to examine potential materiel solutions with the goal of identifying the most promising option, thereby guiding the Materiel Solution Analysis (MSA) phase.

\subsection{Trade Studies}

SWP 6711-00C defines Trade Studies as "iterative studies performed to evaluate and validate concepts representing new technologies, design alternative, design simplification, logistics alternatives and compatibility with the production process." Trade studies continue through the entire acquisition process as a logical approach to selecting the best supportable design, and address the following analyses.

\subsubsection{Identification \& Listing of Functional \& Technical Design Requirements for Tradeoff.}

Identify and list the functional and technical design requirements subject to tradeoff. The functional requirement is listed first, and then related technical design requirements are listed.

\subsubsection{Identification of Possible Design Approaches and Design Characteristics}

Attainable design approaches shall be pursued considering technical capabilities, cost, time schedules, system effectiveness, risk, and resources limitations or other constraints as specified in system requirement documentation. The significant characteristics shall reflect predicted impact on such factors as cost, maintainability, reliability, personnel and training requirements, technical order, schedules, performance, survivability, safety, growth potential, facilities, security, transportability, procurability, and producibility. 


\subsubsection{Comparison Matrix of Design Approaches}

The matrix shall compare the design characteristics for each design approach to determine the degree to which the design approaches satisfy the functional and technical design requirements. The objective is to facilitate rapid comparison and evaluation of potential design approaches and to allow preliminary screening out of those design approaches that are inconsistent with the functional and technical design requirements

RAM requirements must be specified and concepts implemented to ensure system performance goals are met, and that costs are properly balanced so materiel solutions provide capabilities that are effective, suitable, and affordable.

Figure 2 illustrates the outcomes of the trade-offs between Reliability and Maintainability on Availability and Life Cycle Cost (LCC).

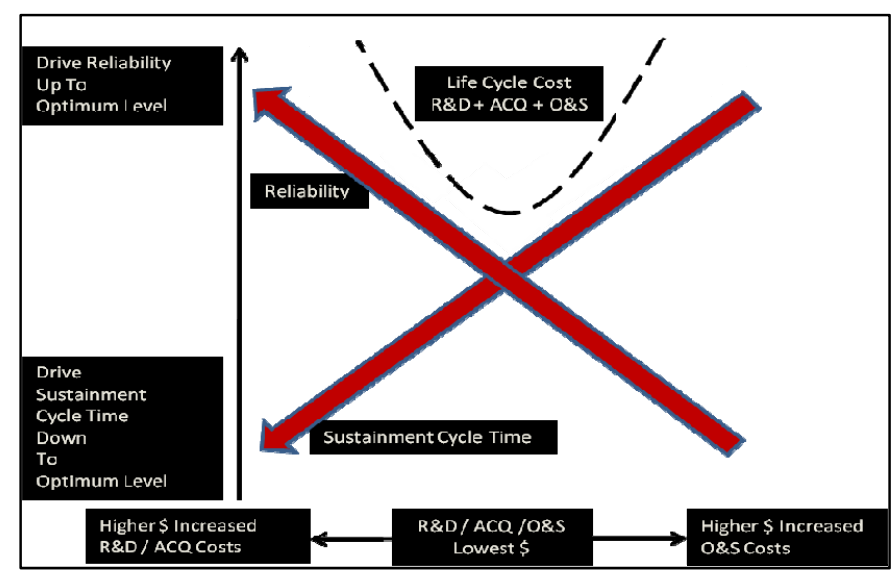

Figure 2-RAM-Life Cycle Cost Trade-off

Systems with low Reliability and high Mean Down Time (MDT) resulting from poor Maintainability will demonstrate low levels of Availability, high Operating \& Support Cost (O\&S) and high Life Cycle Cost (LCC) due to the increased number and length of repair cycles. Conversely, systems with high Reliability and low MDT will demonstrate high Availability, lower Operating Cost and decreased LCC

\subsection{Functional Requirements}

Functional requirements establish the best engineering definition of the usage profile of the system throughout its life cycle, including storage and transportation. They define the requirements that drive the design interface analyses and the resultant logistics support requirements. Key Design Interface criteria include the:

- Physical and operational maintenance environment of the proposed system.

- Functional characteristics of the proposed system, its complexity, and the obstacles and enablers to effective sustainment in operational environment.

- Maintenance capabilities planned for the period in which the system will be introduced.

- Manpower and personnel requirements and constraints in both quantity and skill levels, and use of Product Support
Arrangements.

- Use of technology to facilitate the use of embedded diagnostics, prognostics, and similar maintenance enablers.

- Rough Order Of Magnitude (ROM) Life Cycle Cost estimates (LCC).

\subsection{Reliability, Maintainability, Quality and Availability}

Reliability, Maintainability, Quality and Availability requirements imposed or analyses performed to insure that the system:

- Is operationally ready for use when needed

- Will successfully perform assigned functions

- Can be effectively operated and maintained.

\subsection{Design Analyses}

Design analyses are conducted to assess the features of the design that enhance Reliability, Maintainability and Supportability. They include Failure Mode, Effects and Criticality Analysis (FMECA), where significant information such as the identification of single points of failure is derived.

\subsection{Parts and Materials Selection}

Parts and materials selection criteria are based on objectives defined in the Acquisition Strategy and the Life Cycle Support Plan (LCSP), to include:

- Identification of a preferred parts list

- Definition of the processes for conducting trade-off analysis, parts selection, inclusion of configuration identification status and related change decisions in the technical baseline, and approval and documentation of non-preferred parts

- Discussion of how parts management considerations will flow down to suppliers

Parts selection should be based on trade-off and costbenefit analyses that are conducted in accordance with the program's parts strategy and management plan, as derived from the overall acquisition and sustainment strategies.

\subsection{Design Limit Life Testing}

Testing is conducted to measure the performance of hardware and software configuration items to determine compliance with performance/design specifications, software requirements and interface specifications.

\subsection{Design for Testing/Built-In-Test (BIT)}

The objectives of Designing for Testing are to achieve the required performance monitoring, fault detection and fault isolation capabilities at the appropriate maintenance levels via a balanced, cost-effective mix of BIT, semi-automatic and general purpose manual test equipment.

\subsection{Manufacturing Plan Screening}

Manufacturing Plan Screening is conducted to integrate system production, testing and delivery to minimize cost. 


\subsection{Systems Reviews}

The DoDI 5000.02 acquisition process includes the Preliminary Design Review (PDR) and the Critical Design Review (CDR) to ensure requirements are defined, traceable throughout the design and that governance evaluates the effectiveness of their implementation and the implications on performance, cost, schedule and sustainment. The DoD Systems Engineering Process uses the Defense Acquisition Program Support (DAPS) Methodology to review the design and ensure supportability metrics are defined, implemented in the design as criteria, and that the design reflects their impact on the system in meeting performance and sustainment requirements.

\subsection{Test and Evaluation}

Developmental Test \& Evaluation (DT\&E) and Operational Test \& Evaluation (OT\&E) are the principal methods of ensuring the achievement of user needs as expressed in Key Performance Parameters (KPPs) [13].

DT\&E verifies the systems engineering process and must provide confidence that the system design solution is on track to satisfy the desired capabilities. Rigorous component and sub-system DT\&E enables performance capability and reliability improvements to be designed into the system early. DT\&E events should advance to robust, system-level and system-of-systems level T\&E, to ensure that the system has matured to a point where it can enter production, and ultimately meet operational employment requirements.

OT\&E focuses on testing the system in its intended use environment where two primary metrics reign: operational effectiveness and suitability. From both Supportability and Supportability Analysis perspectives, DT\&E and OT\&E combine to provide quantitative measurement and qualitative assessment of both performance in terms of Reliability and Maintainability, and the effectiveness of the Product Support infrastructure and sustainment resources.

\section{REFERENCES}

1. Operating and Support (O\&S) Cost Guide. Cost Analysis Improvement Group (CAIG). Department of Defense. Washington, D.C. September 2008.

2. Design Interface Process. Standard Work Practice 6711011C. US Navy Naval Air Systems Command. Department of Defense. Washington, D.C. August 2010.

3. Product Support Manager Guidebook. Department of Defense. Washington, D.C. September 2011.

4. Logistics Engineering and Management, $6^{\text {th }}$ Edition. Benjamin S. Blanchard. Prentice-Hall, Inc. Englewood Cliffs, New Jersey.

5. Reliability Toolkit, Reliability Analysis Center Rome Laboratories, Rome, NY. 2008

6. Maintainability Toolkit, Reliability Analysis Center Rome Laboratories, Rome, NY. 2008

7. Military Standard 2165, Testability Program For Electronic Systems and Equipment. Department of Defense. Washington, D.C. 1975.
8. Condition Based Maintenance Plus Guidebook. Department of Defense. Washington, D.C. May 2008.

9. Chairman of the Joint Chiefs of Staff Instruction 2700.01C. Department of Defense. Washington, D.C. January 2012.

10. USD(AT\&L) Memorandum, Implementation of Will-cost and Should-Cost and Will-Cost Management. Department of Defense. Washington, D.C. April 22 2012.

11. USD(AT\&L) Memorandum, Better Buying Power: Guidance for Obtaining Greater Efficiency and Productivity in Defense Spending. Department of Defense. Washington, D.C. April 22 2012. September 14 2012.

12. Defense Acquisition Guidebook. Department of Defense. Washington, D.C. July 30 2012. Pg. 680.

13. Defense Acquisition Guidebook. Department of Defense. Washington, D.C. July 30 2012. Pg. 680.

\section{BIOGRAPHIES}

Patrick M. Dallosta CPL

Performance Learning Director

Defense Acquisition University

9820 Belvoir Road

Ft. Belvoir, VA 22060 USA

patrick.dallosta@dau.mil

Patrick M. Dallosta is the Performance Learning Director for Reliability, Availability, Maintainability \& Supportability (RAM\&S). Mr. Dallosta has over thirty years of industry experience in Program Management, Systems Engineering, Reliability Engineering, Supportability Analysis and Logistics. He holds a Bachelor of Science in Electrical Engineering from Christian Brothers University, a Master of Engineering in Industrial Engineering from Texas A\&M University and is a Candidate for a Master of Science in Computer Information Systems. He holds a DAWIA Level III Certification in Life Cycle Logistics, a Level II Certification in Requirements Management, and is an International Society of Logistics (SOLE) Certified Professional Logistician (CPL).

Thomas A. Simcik CPL, CPIM

Chief Logistician

Naval Sea Systems Command

PEO Integrated Warfare Systems

Washington, D.C. 22202 USA

thomas.simcik@navy.mil

Thomas A. Simcik is the Chief Logistician within the PEO Integrated Warfare Systems. Mr. Simcik retired from U.S. Navy at the rank of Commander in 2007 after completing 20 years as a Navy Supply Corps Officer, where he completed tours with the Chief of Naval Operations, the Naval Sea Systems Command and the Defense Logistics Agency, and served in Operations Desert Shield and Desert Storm and Operation Enduring Freedom. He holds a Bachelor of Science in Economics from the University of Pittsburgh, and a Master 
of Science, Systems Management, from the Naval Postgraduate School. He holds a DAWIA Level III Certification in Life Cycle Logistics, and is an International Society of Logistics (SOLE) Certified Professional Logistician
(CPL). He is recognized by the Association of Operations Management (APICS) as a Certified Production and Inventory Manager (CPIM). 